7.

\title{
DESNICA U TJESNACIMA ZANOSA I DUHOVNE OBMANE MEĐURATNE \\ DALMACIJE
}

\section{Tonći Šitin}

UDK: 821.163.42Desnica, V.:111.852

Izlaganje na skupu

Sažetak: Pokretanje pitanja o položaju i djelovanju inteligencije u Dalmaciji između dva svjetska rata zasigurno je opsežna tema i iziskuje znanstvena monografska istraživanja, koja do danas nisu provedena. U ovom radu, koji se bavi uglavnom intelektualnim itinererom Vladana Desnice, ali ne samo njega, moguće je prikazati tek obrise sadržaja i iznijeti neke misli koje dodiruju položaj inteligencije, ali i proturječnosti društva, sukobe u njemu, svjedočanstva o tome do koje su mjere upravo intelektualci interiorizirali rastrganost svijeta u kojem su živjeli. Utoliko su istraživački rezultati povjesničara književnosti, filozofa, estetičara, povjesničara umjetnosti važniji da bi povjesničari imali jasniju slika o tome što sve mora inkorporirati afirmacija nacionalne samosvijesti kao osnovna težnja inteligencije. Sudbina Vladana Desnice čvrsto je vezana uz Split i Dalmaciju, kao da sve duguje ovom duhu, vremenu i prostoru. Svečanost je nalazio u samoći, glazbi, slikanju i poeziji, u želji da sve to poveže i duboko zaroni u izmučene živote svojih junaka. Nije pristajao na reciklaže, svaku je epizodu ispunio činom svoga rijetkog stvaralačkog duha. Croce i njegovo gostovanje u Dalmaciji predmetom su posebne analize. Desnicu je nadahnula njegova sloboda iskaza, otkriće i definiranje sentimento dominante u svemu. Stalno je prolazio kroz spiralu unutrašnjeg pročišćenja, ali za generaciju intelektualaca kojoj je i sam pripadao, a napose za bučnu radničku vrevu po ulicama grada bio je reprezentant standardnih slabosti.

Ključne riječi: Vladan Desnica, Split, Croce, estetika, inteligencija, zatvorenost, glazba

\section{Povijesne PUlsacije KAMENOG GRADA}

D ovoljno je spomenuti tek nekoliko crtica iz biografije Vladana Desnice, ponajprije podatak da je živio i radio u Splitu od 1920. do 1942. godine, pa da to bude dovoljnim razlogom za istraživački interes, koji je ojačan činjenicom nedovoljne historiografske brige za biografije elitnih intelektualaca, prostore njihova življenja i javnog djelovanja. Premda smo se u ovom radu prvenstveno interesirali za Desničine ideje, nismo mogli zao- 
bići ni njegov privatni život, okrenutost unutarnjem svijetu i intimnim čuvstvima ispunjenima lucidnim lirskim govorom daleko od vrtoglavice vanjskog svijeta. Neprijeporno, nije lako pisati o čovjeku čiji je život bio istinski zahvaćen poviješću i politikom (otac), a koji se trudio da tu činjenicu potisne i da njegovi životni afiniteti budu usmjereni prema znanosti, poeziji, glazbi, k tome u gradu opterećenom secesionističkim sjenama u kojemu se novim metamorfozama mogao radovati tek uski krug inteligencije. Zanimljivim se mogu učiniti pitanja poput onoga koliko je povijesna znanost reflektirala vrijednosti pisaca i njihove kulture, koliko je jedan (službeni) pristup povijesti uvažavan više od drugih te zašto smo se više bavili analizom književnih tekstova nego li opservirali kulturnopovijesni kontekst i povijesnu interpretaciju bogatili specifičnim prinosima intelektualnog i kulturnog rada (novi historizam). ${ }^{1}$

Desnica je od ranih početaka svoga književnog rada, koji će istina tek kasnih 1930-ih godina dobiti puni intenzitet, ostao izvan svih književnih struja i pokreta, en vogue trendova koji su dolazili i nestajali. Svoj je izraz gradio na onome što je bilo najdelikatnije i najkrhkije, ali u isto vrijeme autentično, na neposrednim doživljajima, tihim susretima i senzibilitetu Mediterana, ne odričući se prigušenih registara nostalgije i vječne potjere za uzvišenim idealima. Upoznati sebe značilo je odabrati svoje startne pozicije, odrediti se prema književnoj tradiciji, polako izgraditi nesputani stvaralački duh i neprestano provjeravati istinitost i utemeljenost svojih paradigmi. Vrijedno je primijetiti da je Desnica stalno računao na važnost kritičkih pozicija i da najčešće zaokruženi i povezani zaključci - bilo da je riječ o književnosti, znanosti, politici ili glazbi - svjedoče o istom zanosu i istim estetskim kategorijama. Ujedno su i biljeg umjetnika koji je bio strasno saživljen $s$ unutrašnjim pejzažima Zadra, Splita i Dalmacije, tajanstvenim životom gotovo mitološkog značenja. Neophodno je podvući da se Desnica rano suočavao s pitanjima intelektualnog angažmana u raznim situacijama i svakodnevnim teškoćama i neprilikama. Svaka ideološka diskvalifikacija i dogmatizmi raznih izvorišta bili su mu strani, premda je kasnije u poznatim polemikama o svojim djelima pokazivao vještinu, analitičnost i strast, odbacujući „nesporazume“, brojne napade zbog „primijenjene književnosti“ i primjedbe da mu je stil suho intelektualan, hladan, pesimističan pa i lažan. ${ }^{2}$

Svojom širokom naobrazbom i iskazanim interesom za sve manifestacije života, Desnica je postupno pronašao umjetnost kao područje koje mu je najviše odgovaralo i koje je bilo prava opreka birokratskoj jednoličnosti, uključujući i juridičku karijeru koja mu je osiguravala standarde građanskog života. Povremeno se javlja i u novinama, koje su otvorile svoje stranice modernom hrvatskom jeziku i u kojima se registriraju događaji koji nisu tek političke vijesti te koje, oslobođene skrbnišstva i bijesa cenzure, hitaju novim temama i odbacivanju zaostalih uspomena na crno-žutu monarhiju. U gotovo zatvorenom bidermajerskom svijetu Desnica je u tišini slijedio svoje poticaje i u poeziji pronalazio rafinirani uži-

1 Ken Wolf, Personalities \& Problems, Interpretive Essays in World Civilization, New York 2005.; Michel Foucault, Riječi i stvari, Zagreb 2002.; David Šporer, Novi historizam. Poetika kulture i ideologija drame, Zagreb 2005.; Ante Cettineo, Grebeni se rone, Split 1928.

2 Vladan Desnica, Progutane polemike (prir. Jovan Radulović), Beograd 2001. 


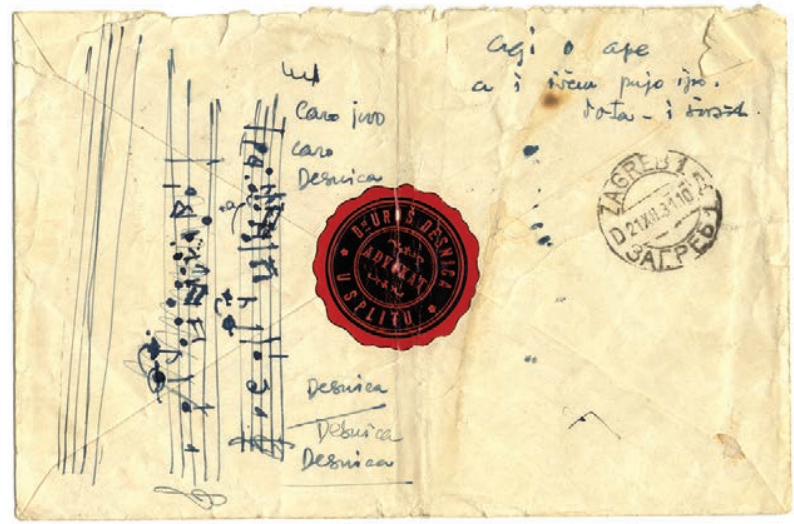

Sl. 1. Vladan Desnica je ponekad kratio svoje pripravničke odvjetničke dane varirajući glazbene motive na očevim službenim dokumentima. Reproducirana omotnica zapečaćena je odvjetničkim pečatom dr. Uroša Desnice. tak, a neostvareni glazbenik i slikar svoje je talente pretočio u rijetku literarnu snagu retoričke i tonske uglađenosti. Sjećajući se njegovih mladih dana, prijatelj Vladimir Rismondo bilježi da je Vladan već tada „bio također i čovjek akcije i on je u književnu akciju unosio onu istu točnost i savjesnost, koje su predstavljale karakteristiku svih njegovih postupaka u privatnom životu“. Jedino u stihovima mogao je pjesnik ,iskazati svoj osobni stav i odnos prema životu sa svom njegovom dubokom i teškom patetikom", kao što je kao lirik mogao neposredno doživjeti „oslobođenje koje se u najvećoj mjeri crpe iz onog stvaralačkog saznanja što se dostiže u času kad se lična misao i lična patnja sasvim prenesu u muziku stiha, koja u ovom času predstavlja element same vječnosti“. 3 Predanost literaturi i umjetničkom izrazu bila je kod Desnice konstanta, kao što je u opisu događaja ostajao psihološki vezan uz likove i njihove sudbine, a ne udaljeni i hladni promatrač koji ne zna za strah i tjeskobu, udarce života i bol. U poučnim „Zapisima o umjetnosti“ Desnica upozorava da je svaka „iskrenost u stvari iskrenost o samome sebi“. Dok realnost nema potrebe da bude uvjerljiva jer za sebe ima istinitost, umjetnost naprotiv „čitava živi od uvjerljivosti“. Trebalo je dugo iskustvo i samom Desnici da spozna kako nije cilj pisanja napisati „što ljepše ili što je bolje moguće“, već naprosto „izraziti točno ono što se je htjelo reći“ ${ }^{4}$ Kada se nakon 1949. profesionalno bavio isključivo književnošću i živio u Zagrebu, što je bila izuzetno hrabra odluka, bio je vrlo aktivan, a mladi krugovaši prihvatili su ga kao modernista, premda je živio svojim usamljeničkim i neovisnim građanskim životom, izložen gorčini indoktriniranih kritičara kojima je smetala profilirana senzibilnost, kontemplativnost i otmjenost duha.

\section{Obzori Mediterana}

Slike sretne i zanosne Dalmacije nakon 1918. brzo su kopnile. Kao da je snažna bura rastrgala krhke fasade i od lirske poeme nakon nekoliko godina života Kraljevine SHS nije ostalo gotovo ništa. Urednik Novog doba Vinko Kisić potreseno konstatira: „Razočarani oni - razočarana i ona.“ Ipak, upozorio je da na „kršu dalmatinskom stvara odbrana državnog integriteta (...) na žalu dalmatinskom otvaraju se vrata Jugoslaviji u svijet."5 Psiho-

\footnotetext{
Vladimir Rismondo, Oblici i slova, Split 1979., 212-213.

4 V. Desnica, „Zapisi o umjetnosti“, Progutane polemike, 11-23.

5 Vinko Kısıć, „Problemi Dalmacije (politički i ekonomski)“, Nova Evropa, 15/1927., br. 3-4, 77.
} 


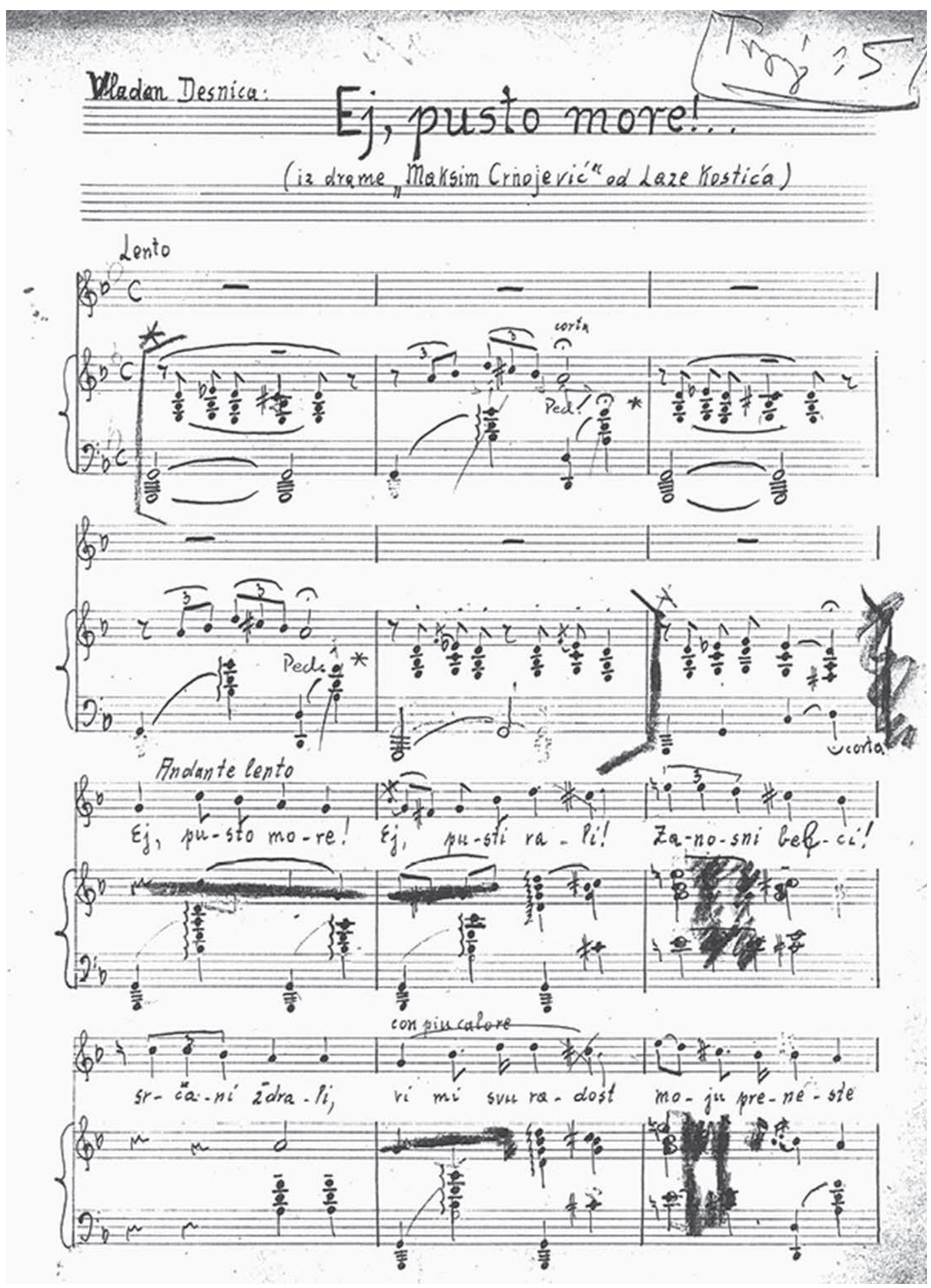


loška kompleksnost secesionističkog Splita dugo je određivala intimno tkivo grada koje je bilo opterećeno prometnom izoliranošću, gospodarskim zaostajanjem i neriješenim posjedovnim odnosima. Pojava velikog broja stranaka nakon 1918. godine u novoformiranoj monarhiji bjelodano je svjedočila o opsesivnoj potrebi da se donekle politički artikulira jedan podijeljeni i nerazvijeni socijalni, kulturni, nacionalni i vjerski front, što će na teškom drumu centralizma ubrzati procese nacionalne identifikacije i prepoznavanja „drugih “ kao krivaca. Trebat će proći neko vrijeme da granice i „neprijatelj“ odigraju veću ulogu u stvaranju nacionalnog identiteta, dok će stvaranje stranke-države (HSS) svoju misiju konstituiranja nacije vidjeti u mobilizaciji etnički i kulturno raznorodne populacije. Nacionalizam je dominantna religija modernoga zapadnog svijeta (Toynbee). ${ }^{6}$

Pokretanje pitanja o položaju i djelovanju inteligencije u Dalmaciji između dva rata zasigurno je opsežna tema i iziskuje znanstvena monografska istraživanja, koja do danas nisu provedena. U ovom radu koji se bavi uglavnom intelektualnim itinererom Vladana Desnice, ali ne samo njega, moguće je prikazati tek obrise sadržaja i neke misli koje dodiruju položaj intelektualaca i njihov angažman, ali i proturječnosti društva, sukobe u njemu, svjedočanstva o tomu do koje su mjere upravo intelektualci interiorizirali rastrganost svijeta u kojem su živjeli. Utoliko su istraživački rezultati povjesničara književnosti, filozofa, estetičara, povjesničara umjetnosti važniji da bi povjesničari mogli stvoriti jasniju sliku o tomu što sve afirmacija nacionalne samosvijesti kao osnovna težnja inteligencije mora inkorporirati. Ako inteligenciju motrimo kao društveni sloj koji je određen funkcionalnim, formalnim i statusnim kriterijem, on još uvijek nije egzaktno omeđen i objektivno vrednovan jer nije istraženo socijalno i političko ponašanje inteligencije. To je posebno delikatno u slabije razvijenim društvima u kojima inteligencija, uključena u građansku klasu, ima snažniju društvenu ulogu nego li joj po vlastitoj snazi pripada. Pored „političke inteligencije" koja oblikuje i vodi političke stranke, smatrajući se često jedinim zastupnikom nacionalnih interesa, postoji i ona inteligencija koja se vezuje za rad kulturnih ustanova i njihove raznolike djelatnosti pa nedostatak profesionalnih analitičara društva nadomještaju književnici i drugi intelektualci koji proniču i izražavaju dileme društva. Dvadesetih godina 20. stoljeća na sceni su još intelektualci formirani u Austro-Ugarskoj, što je bitno utjecalo na njihovu formalnu, idejnu i psihološku profilaciju (mahom su u upravim službama, humanistički obrazovani). Tridesetih godina, s produbljenim krizama, inteligenciju je zahvaćao sve jači politički pragmatizam. Malo je bilo onih koji su bili free lancer i borili se protiv krize i za neke druge vrijednosti. Borbe su se vodile u situaciji „moralne migrene“, kako bi to rekao Krleža, pojačane brigom za posao i održanje obitelji, a produbljivao se i totalitet nacionalne problematike. Dug je put do analize sociološke strukture i političke angažiranosti. S vremenom se formirala i nova intelektualna elita koja je gubila izravnu vezu s pojmom klase. Moglo bi se kazati da nastavljala djelovati baštinjenim slijedom kao arbiter elegantiarum. Intelektualci su postajali svojevrsni suci ukusa, dakako oni među njima koju su umjeli shvatiti njegove epohalne kriterije. Arnold Toynbee govori o intelektualnoj

6 Arnold J. Toynbee, A Study of History, 1-10.vol abridg., Oxford 1987.; Edgar Morin, „Sastavnice nacionalnog osjećaja“, Lettre Internationale, 1/1991., br. 3-4, 17. 
birokraciji u sferi književnosti i kulture koja daje/stvara učesnike i promatrače bez revolucionalnog stava. Ta intelektualana elita djeluje na principu antipatije, logikom podjela na one koji razumiju i ne razumiju.

Zanimljiva je analiza mađarskog znanstvenika Andrása Bozókija koji istražujući današnje tranzicijske probleme u istočnoeuropskim zemljama iznosi stavove o intelektualcima koji se dijelom odnose i na našu situaciju. Bozóki upozorava da se termin „intelektualac“ ne treba dovoditi ni u kakvu vezu sa ostvarenom zajednicom-kolektivitetom. Razloge autor vidi u činjenici da intelektualci ne posjeduju nikakav oblik klasne svijesti i njihov dolazak na vlast potkopava klasno inspirirane akcije. Bozóki također upozorava da termin „inteligencija" obrazovane i progresivne građane baca na margine službene elite. Za razliku od intelektualaca, inteligencija se nastoji predstaviti kao svjesni kolektivitet koji ustaje protiv zadržavanja statusa quo. Autor navodi i znanstvenike poput Mannheima, Gramscija, Gouldnera, Bourdieua, Pareta i drugih koji istražuju poziciju intelektualca kao vlasnika specifičnog kulturnog kapitala koji nam pomaže da shvatimo poruke i potrebe društva i vlasti, ali i da u isto vrijeme grade alternativne oblike svijesti i realnosti koja se mijenja. ${ }^{7}$

\section{Croce: UMjetnost KaO AUTEnTIČni NAČIn ŽIVOTA}

Ne bi se moglo kazati da je Split u međuratnom razdoblju bio pokretačem značajnih doprinosa na području teorije umjetnosti, napose estetike, premda su pokušaji Ljudevita Dvornikovića za stvaranjem estetike Moderne i kritike ovdje bili poznati, pogotovo stav da bit umjetnosti nisu istina i spoznaja već doživljaj. Slično je bilo i s Albertom Bazalom i njegovim doprinosima u vrijeme Moderne koji će kasnije u 20. stoljeću u prvi plan isticati borbu protiv doktrine jugoslavenske nacionalističke umjetnosti i onih umjetnika koji su je tada u krugu oko mladog Meštrovića zagovarali. Ako je Albert Haler bio taj koji je u hrvatskoj kulturi prvi otkrio Crocea u međuratnom razdoblju ${ }^{8}$ - premda su Kršnjavi i Livadić za njega znali i prije - onda je sasvim izvjesno da Croceova estetika u Splitu i Dalmaciji imala svoje velike promotore u Vladanu Desnici i Vladimiru Rismondu. To je bio doprinos koji je Splitu, a preko Halera i cijeloj Hrvatskoj, osigurao izravnu vezu s najaktualnijim filozofom umjetnosti i estetičarom koji je imao vrlo velik utjecaj ne samo u Italiji već i u cijelom svijetom. Štoviše, Rismondo je tada sebe otvoreno nazivao „kročeancem“ koji istražuje i slijedi njegov put povezivanja estetike i filozofije, odnosno povijesti. Croceova estetika i poznati Brevijar estetike bili su odgovori na pitanja što umjetnost jest a što nije, što je lijepo a što nije. Croce je poistovjetio filozofiju umjetnosti i estetiku s filozofijom jezika. ${ }^{9}$ Umjet-

\footnotetext{
András Bozóki, Intellectuals and Politics in Central Europe, Budapest 1999., 44-48.

Albert Haler, Doživljaj ljepote, Zagreb 1943.

9 Benedetto Croce (1866. - 1952.) bio je talijanski filozof, političar, povjesničar umjetnosti i književni kritičar. Rezultate svojih istraživanja tiskao je u časopisu La critica, koji je pokrenuo 1903. s Giovannijem Gentileom, filozofom i političarom, autorom Doktrine fažizma. Najvažnije Croceovo djelo je Filosofia come scienza dello spirito (Filozofija kao znanost duha) u četiri toma. U njemu obrazlaže svoje estetske stavove oslobođene metafizičke doktrine i pozitivizma, s fokusiranjem čiste intuicije koja prethodi svakoj akciji duha. Usp. Giuseppe Galasso, Croce e lo spirito del suo tempo, Milano 1990.; Gennaro SAsso, Filosofia e idealismo, sv. 1: Benedetto Croce, Napoli 1994.
} 
nost je za njega čista intuicija oslobođena suda ako je rezultat „čiste lirike“. Umjetnost je aktivni odnos prema životu, sve što se izražajnom formom i prenosi u umjetnička djela je estetika. Umjetnost je protivnost svakom praktičnom aktu, ona je lirski zanos umjetnika. Ipak, cijeli taj poduhvat je ostao u idejnim granicama 19. stoljeća, zapravo riječ je bila o kraju estetike 19. stoljeća. Croce nije razumio što je donosila postmoderna, njegov je svijet i duhovno hranilište klasika. Croce je inače bio shvaćan kao teoretičar ukusa, kao odvjetnik autonomije umjetnosti, kao odrednica što treba a što ne. Stječe se dojam da je takva apsolutizacija dobrog ukusa nama tada nedostajala. Trebala nam je obrana od pozitivizma i pritiska ideologije. Tu se smještaju Desnica i Rismondo i cijela grupa prijatelja - Zuppa, Cettineo, Šegota, Steg, Peruzović, Jutronić, Vjeko Parać, Hranko Smodlaka, Dešković, Job, Ivo Parać i Čičin Šain. U to vrijeme (1935.) tiskan je i poznati Rismondov članak „Za jednu dalmatinsku kulturnu orijentaciju“ u Magazinu Sjeverne Dalmacije. U njemu je Rismondo upozorio na pojavu neke nove kulturne orijentacije koja zaboravlja dalmatinsku prošlost i domaću kulturu. Štoviše on zagovara „dalmatinsku književost“, tradiciju, kozmopolitski duh, što je svojevrsni programatski članak o mediteranizmu..$^{10}$ „Naše se pitanje“, ističe u članku Rismondo, „,svodi na zahtjev jedne normalnije i logičnije kulturne orijentacije, i to takove jedne orijentacije, koja će već samim svojim postulatima učvrstiti znatno već olabavljelu ili još potpuno neprekinutu vezu između današnjeg kulturnog $s$ jedne i istoričkog Dalmatinca s druge strane i tako dovesti prvog natrag u sklad i sa samim sobom i sa sredinom u kojoj živi i kojoj kao misaona jedinica čitav pripada. Drugim riječima, dalmatinski književnik i intelektualac treba da se mnogo više nego što to danas radi posveti upoznavanju svoje domaće kulture, onamo od prvih latinskih i slovinskih kroničara i začinjavaca pa sve do Đorđića i Kačića, a isto tako i intenzivnom proživljavanju svih onih socijalnih i kulturnih činjenica koje su se, paralelno i simultano s njegovim domaćim, na otvorenom Mediteranu zbivale i uvijek se na njih uticale." ${ }^{11}$ Prisjećajući se mnogo godina kasnije tih emocijama ispunjenih dana, profesor Rismondo je nesuspregnuto pričao kako su njega i grupu studenata u Zagrebu neki ljudi pogrdno nazivali „rasica“, najvjerojatnije pod dojmom njihove osamljenosti i izdvojenosti, pa je i sam uvidio koje mogu biti posljedice prekidanja veza s tradicijom, utjecajnim ljudima i autentičnom kulturom europskog značenja. Napadi su bili takvi da je autor nazivan autonomašem, da razbija jugoslavensku orijentaciju i da se zalaže na nekakvu nehrvatsku Dalmaciju!!2 U polemiku u časopisu Kolo uključila se i mlada povjesničarka Nada Klaić (1966.) i diletantima nazvala one koji su Rismonda ocijenili nekritičnim povjesničarom. ${ }^{13}$ Tako su se neke Croceove ideje, eto, s domaćim modifikacijama našle na repertoaru dalmatinske kulturne scene prvenstveno kao otpor nacionalnim centrima i agresivnom nametanju vrijednosti koje su se nazivale modernima, a zadatak je bio da se stari umjetnički oblik spasi od zaborava i time dade biljeg vječnosti. Konačno, dalmatinski su umjetnici imali intenzivne doživljaje, ali i intelektualne sadrža-

10 Vladimir Rismondo, „Za jednu dalmatinsku kulturnu orijentaciju“, Magazin Sjeverne Dalmacije, br. 2, 1935., 111116.

11 Isto, 114.

12 „Vraćanje tradiciji“, Nedjeljna Dalmacija (Split), br 206, 20. 4. $1975 ., 7$.

13 Nada Klaić, „Diletantizam“, Kolo, 4/1966., br. 7, 102-103. 
je, što je svemu davalo posebni smisao. Antagonizmi, sukobi interesa i ideja, svjetonazora i političkog grupiranja zaokupljali su čak i privatne sfere, razgovori o potrebi pronalaska modus vivendi osvojili su i ulice. Tamo se baš probijala vijest da je pisac Đuro Vilović u svom feljtonu lansirao nadimak „rasice“ za one Dalmatince koji nisu bili uz zajedničare, koji su navodno bili bliski Beogradu i sada još prizivaju popularnog Crocea da ih poduči. ${ }^{14}$ A radilo se o tome da je općoj pasivnosti duhova zaprijetio gubitak sebe, da se ugledamo u druge, da svoje zaboravimo unatoč ćinjenicu da je jedna dalmatinska a u isto vrijeme i slavenska i zapadna književnost sačuvala i nudi svoju autonomnu duhovnu svijest! Simbol takve nove, mudre i osviještene Europe bio je u tom trenutku Benedetto Croce, koji je na širokom polju umjetnosti i duha pokušao zaustaviti pad. Odredio je intuitivnu i logičku ljudsku spoznaju, s tim da je prednost dana estetici u okvirima intuicije - umjetnička istina neovisna je o znanosti i služi afirmaciji autonomne pozicije estetike. Za Crocea umjetnost ne mora predstavljati stvari onakvima kakve jesu, ona je takvih obaveza oslobođena. Razumije se da je u atmosferi pritisaka i povlačenja ovakav svježi vjetar dočekan raširenih ruku, teorija o jedinstvu unutrašnje aktivnost duha, povezanosti estetike i ekspresije, kritika kao umjetnost, odbacivanja pozitivizma, ideje su koje su brojne pristaše autonomije stvaralaštva brzo prihvatile. Vladanu Desnici Croceova Estetika, pobjeda samosvojnosti i nezamjenjivosti kao da je bila dodatna motivacija za ustrajnost, za oslobađanje od svake trivijalnosti i konačno vrijeme za potpuno sazrijevanje i novu fazu autentičnog života koji je nadmoćan drugim oblicima egzistencije. ${ }^{15}$

U atmosferi kada je život na Balkanu obilovao velikim obratima i kada je sve vrvilo od fraza i političkih deklaracija sredinom dvadesetih godina 20. stoljeća, Europa je bilježila tehnički napredak, novi oblici komunikacije, kao i veze između umjetnika i intelektualaca su ojačali. Masovni spektakli fascinirali su svijet, polako se slutio nastanak novog kulturnog prostora.

Sasvim je izvjesno da svaki književnik ili intelektualac ne osjeća želju da se posveti politici. Odabiranje posebnih zadataka u struci, politička pasivizacija i izbjegavanje javnosti kao da je najčešća svakodnevica intelektualaca. Ako je danas zadatak modernog intelektualca da osigura funkcioniranje određene doktrine ili nekog od lidera ideološkog pokreta, to se smatra izuzetno važnim postignućem, ${ }^{16}$ ali ako bi se pitalo Desnicu, onda je zadatak umjetnosti rušiti svijet na umoru i obnavljati nove životne principe. ${ }^{17}$

$\overline{14}$ Usp. Josip Horvat, Živjeti u Hrvatskoj 1900. - 1941., Zagreb 1984., 232.

15 Benedetto Croce, Književna kritika kao filozofija, Zagreb 2004.; Benedetto Croce, Estetika kao znanost izraza i opía lingvistika, Zagreb 1991.

16 Edward SHILs, The Intellectuals and the Powers and Other Essays, Chicago 1972.

17 Vladan Desnica, Eseji, kritike,pogledi Vladana Desnice (= Sabrana djela Vladana Desnice, knj. IV), Zagreb 1975.,195. 


\section{Desnica Between the Sraits of Enthusiasm and Spiritual Delusion of Interwar Dalmatia}

Posing a question on the actions and position of the interwar Dalmatian intellectual class is surely a vast topic which requires scientific research that has not yet been undertaken. This paper delves mainly into the intellectual itinerary of Vladan Desnica, among other matters, but it can only attempt to sketch some content and thoughts which touch upon the position of the intellectual class, as well as the social contradictions, social conflicts, testimonies to the fact that intellectuals interiorized the rupture of the world they inhabited. This makes the research done by historians of literature and art, philosophers and aestheticians important for creating a clear image of what should incorporate the affirmation of national consciousness as the basic aspiration of intellectuals. The fate of Vladan Desnica is tightly connected to Split and Dalmatia, it is as if he owes everything to this spirit, time and space. He found ceremony in loneliness, music, painting and poetry, in his wish to connect this, delve deeply into the tortured lives of his heroes. He did not accept recycling, every episode was penetrated with acts of inspiration. Croce and his stay in Dalmatia is specifically analyzed, Desnica had been inspired by his freedom of expression, the revelation and defining of a „sentimento dominante“ in everything. He perpetually passed through a spiral of inner purification, and for the generation of intellectuals accompanying him until the war, and for the clamour of labourers in the streets he was a representative of the usual weaknesses.

Keywords: Vladan Desnica, Split, Croce, aesthetics, intellectuals, close mindedness, music

\section{$\cos$}

\section{Literatura}

András BozóкI, Intellectuals and Politics in Central Europe, Budapest 1999.

Ante Cettineo, Grebeni se rone, Split 1928.

Benedetto Croce, Estetika kao znanost izraza i opća lingvistika, Zagreb 1991.

Benedetto Croce, Književna kritika kao flozofija, Zagreb 2004.

Vladan Desnica, Eseji, Kritike, Pogledi (= Sabrana djela Vladana Desnice, knj. IV), Zagreb 1975.

Vladan Desnica, Progutane polemike (prir. Jovan Radulović), Beograd 2001.

Ljubodrag Dimıć, Kulturna politika u Kraljevini Jugoslaviji 1918-1941, 3 sv., Beograd 1996. 1997.

Michel Foucault, Riječi i stvari, Zagreb 2002.

Giuseppe Galasso, Croce e lo spirito del suo tempo, Milano 1990.

Albert Haler, Doživljaj ljepote, Zagreb 1943.

Josip Horvat, Živjeti u Hrvatskoj 1900. - 1941., Zagreb 1984.

Vinko Kısıć, „Problemi Dalmacije (politički i ekonomski)“, Nova Evropa, 15/1927., br. 3-4, 73-78.

Nada Klaić, „Diletantizam“, Kolo, 4/1966., br. 7, 102-103.

Edgar Morin, „Sastavnice nacionalnog osjećaja“, Lettre Internationale, 1/1991., br. 3-4, 16-18. 
Vladimir Rismondo, Oblici i slova, Split 1979.

Vladimir Rismondo, „Za jednu dalmatinsku kulturnu orijentaciju“, Magazin Sjeverne Dalmacije, br. 2, 1935., 111-116.

Gennaro SAsso, Filosofia e idealismo, sv. 1: Benedetto Croce, Napoli 1994.

Edward SHils, The Intellectuals and the Powers and Other Essays, Chicago 1972.

David Šporer, Novi historizam. Poetika kulture i ideologija drame, Zagreb 2005.

Arnold J. Toynbee, A Study of History, 1-10.vol abridg., Oxford 1987.

„Vraćanje tradiciji“, Nedjeljna Dalmacija (Split), br 206, 20. 4. 1975., 7. 